\title{
Working With Younger-Arriving ESL Learners in High School English: Never Too Late to Reclaim Potential
}

\section{Hetty Roessingh and Pat Kover}

\begin{abstract}
Younger-arriving ESL learners often come to high school ill prepared for the demands of English literature courses. Although they may have acquired the phonological and grammatical system of English with relative ease and developed a basic vocabulary, they lack the breadth and depth of vocabulary and the related concepts that are necessary to engage with the abstract nature and cultural embeddedness of literature study. In probing behind this linguistic façade, we have been able to help our students make gains in the development of cognitive academic language proficiency as reflected in standardized achievement measures of academic writing. The acquisition of the cultural capital necessary for success in literature studies, however, is more problematic. New questions arise about student identity and cultural understandings that are central to the success of ESL learners in high school.
\end{abstract}

Les étudiants en ALS qui arrivent à l'école secondaire alors qu'ils sont plus jeunes que leurs pairs sont souvent mal préparés face aux exigences des cours de littérature anglaise. Même quand ils ont réussi relativement facilement à acquérir les systèmes phonologique et grammatical de l'anglais et à développer un vocabulaire de base, il leur manque la précision et la richesse lexicales ainsi que les concepts connexes qui sont essentiels à l'étude abstraite et enracinée dans la culture qu'est celle de la littérature. En allant au-delà de cette façade linguistique, nous avons pu aider nos étudiants à faire des progrès dans le développement de leur compétence langagière sur les plans académique et cognitif, telle que reflétée par les évaluations standardisées de rendement en rédaction académique. Par contre, l'acquisition du capital culturel nécessaire à la réussite des études littéraires est plus critique et fait ressortir des questions sur l'identité des étudiants et la sensibilisation à la culture qui sous-tendent la réussite des apprenants en ALS à l'école secondaire.

\section{Introduction}

Twice a year, after the grade 12 Alberta Provincial Diploma examination results are released, high school principals are anxious to study and interpret the results as these may reflect on identified school-level issues and the school improvement plan that principals must submit to the Chief 
Superintendent's office each September. One day in February 1998, I received a call from the principal of the school where I was then the ESL teacher, summoning me to her office. There was an edge to her voice, forewarning me of "something up." I arrived at her office. Her desk was covered with Diploma exam results. I noticed a curious pattern of red-circled marks, all devastating failures in the English literature departmental examination and all clearly names of Chinese origin. "Are these yours?" she queried. I scanned the list, not recognizing any of them as mine. Almost instantly, I recognized the challenge ahead.

About the same time, a young student from Hong Kong arrived at the door of my ESL classroom. Politely introducing himself, he indicated that he had heard that perhaps he could get some help. Now 15, he had been in Canada since grade 2. Academic work had become increasingly difficult for him. Yet he had the learning profile of an academic student, and there were family expectations for his future success. What could we do?

Younger-arriving and Canadian-born ESL learners face special challenges in developing the level of English language proficiency required for academic success and university entrance. Our understanding of the patterns of second-language acquisition as this relates to youngsters' cognitive development and subsequent academic success is still in its infancy, and remains shrouded in conventionally held beliefs among educators-English as a second language (ESL) and mainstream English language teachers alike. What follows is a report of a collaborative effort between two colleagues, an ESL teacher and English department head. The purpose of this article is to unmask the myths surrounding the ease with which youngsters acquire a second language. We present the results of a three-year project that intervened in the educational trajectory of these at-risk learners by providing direct ESL support, beginning in their grade 10 year, and following them through to grade 12.

We begin with background information about the shifting demographics in Canada's immigrant population, a phenomenon we believe may well be common to other provincial as well as national jurisdictions. Then we provide information relevant to second-language acquisition among young ESL learners, as well as some information about mainstream teachers' perceptions of ESL learners. To provide the reader with a context for the work we undertook, we describe our school demographics and school culture. We present the evaluation results of the January 1998 cohort of ESL learners taking the English literature course (the school-based mark and examination mark). We also present their mathematics scores. This sets the research question and the context for the curriculum work within the ESL program and the English department that would begin to address failure among academically competent ESL learners at this late stage of their educational experience in Canada. We describe our plan for intervening in the cycle of 
failure by providing the direct support believed necessary to reclaim lost potential and set the students up for success by grade 12 . We provide results of a comparison group of students who succeeded in completing university entrance requirements in 2001 and who we believe are positioned for future academic studies at the university level. Finally-and we provide some tracking data of the 1998 cohort-all attempted university level studies. We interpret and discuss these results in the light of the research literature, and we challenge some of the earlier findings and the popularly held beliefs. We conclude with a call for better identification of at-risk ESL learners who arrived at an early age or were Canadian-born and for the provision of direct ESL support that is monitored and adjusted as they move toward high school, graduation, and university entrance.

\section{Background}

Large urban school districts have experienced a significant intake of ESL learners at the Division 1 (grades 1-3) and Division 2 (grades 4-6) levels over the past decade, largely as a consequence of the federal government's reshaping of the immigration policy in 1985 (Employment and Immigration Canada, 1985). Recognizing that Canada had an aging population and a negative birth rate, paired with an economic strategy for moving Canada forward into what has been termed the third economy - one based on information-processing, knowledge, and leading-edge technology-Canada's federal government embarked on a campaign to attract the world's brightest and best to renew Canada's human resources. Business and skilled worker class immigrants were given priority, and they brought with them their young families, or had their children in Canada. Most of Canada's new arrivals continue to come from the Pacific Rim, and the children's first language is usually Cantonese, whether they are Canadian or foreign-born. The demographic profile that emerges is of young, academically competent ESL learners who have eventual expectations for university-level studies.

Early studies in second-language acquisition picture this process as natural and as unproblematic as when a child acquires a first language. Young children appear to master certain aspects of their second language (L2) to native-like proficiency with ease. Oyama (1976) finds that children who begin learning English before age 11 perform like native speakers on tasks of phonological output. Similarly, in a meta-analysis of studies pertaining to acquisition of syntax, morphology, pronunciation/speech fluency, Krashen, Long, and Scarcella (1979) report that younger children outperform older children and adults in eventual attainment on these measures. In short, once children "sounded good" in English, they were once thought to have mastered the language; communicative competence was equated with full proficiency in L2. The idea of a critical time believed ideal for L2 acquisition 
had its origins in this early research (Snow \& Hoefnagel-Hohle, 1978) and remains prevalent today.

Twenty years ago, however, Cummins (1982) challenged the notion of the adequacy of communicative competence for engagement in academic tasks. Cummins posited a conceptual framework for the development of English language proficiency (ELP) along two continua: from cognitively undemanding to cognitively demanding, and from context embedded to context reduced language. The important understanding that emerges from this framework is that ELP develops in contexts for language use that have been coined Basic Interpersonal Communication Skills, or BICS, and Cognitive Academic Language Proficiency, or CALP. BICS-level communication skills may be acquired by learners of all ages within approximately two years of arrival. This is consistent with the early studies on L2 acquisition cited above. On the other hand, CALP-level proficiency required for successful engagement with high school literature courses where the language of metaphor, imagery, and symbolism is prevalent may take seven (or more) years to develop. This finding has a direct impact on how younger-arriving immigrant children are perceived and assessed by their teachers. The linguistic façade presented in fluency of conversational English may later serve to the children's detriment, as shown below. Olague (1993), a Hispanic immigrant, now a successful teacher, recalls her humiliation and embarrassment as a young grade 3 student in not being able to comprehend her teacher's reading of a poem. She alludes to this phenomenon of linguistic façade and the teacher's inability to look beyond her young pupil's apparent communicative competence, and hence respond appropriately to her evolving learning needs. Fortunately for the young but self-possessed Olague, she had an inner sense of her intelligence regardless of her teacher's perception of her. Many young ESL learners are not so lucky.

Cummins (1981) further highlights the influence of first-language (L1) development on eventual achievement in L2 development. Students can use concepts and knowledge developed in L1 to make the L2 input comprehensible; concepts developed in L1 can easily be transferred to L2 given adequate exposure to L2. There is a common underlying proficiency that flows between L1 and L2, and thus the better L1 is developed, the more likely L2 will develop to the level required for academic success. Conversely, failure to develop the $\mathrm{L} 1$ beyond a basic level may have dire consequences for the development of the L2. The L2 must overtake the L1 to become the dominant language for communication, thought, and engagement in academic tasks at an abstract level, a significant challenge for youngsters whose L1 is Cantonese and who maintain their L1 only for conversational purposes in the family and cultural community in their adopted second home. Indeed, Collier (1995) notes the amount of formal schooling students have received in their first language as the critical variable in students' academic achievement 
in their second language. She identifies grade 4 as the linguistic threshold required in an $\mathrm{L} 1$ for smooth transfer to the $\mathrm{L} 2$ of underlying concept understanding central to cognitive development. Collier further argues for the ongoing simultaneous development of language and cognition in both L1 and L2 in order for ESL learners to realize their full academic potential.

What emerges from the background information presented above is a generation of young-arriving ESL learners (together with Canadian-born ESL learners) who appear to have mastered English to a level sufficient to experience success in the educational mainstream settings where they were integrated at an early stage. By the early 1990s it was common practice to mainstream these children in regular classrooms. It was also an era of fiscal restraint in many educational jurisdictions ( $\mathrm{Neu}, 2000$ ), and ESL programming was targeted for severe cutbacks. The "younger the better" thinking prevailed among administrators charged with making budget decisions, and ESL support was virtually eliminated at the elementary level. It was assumed that these ESL learners would simply acquire CALP-like proficiency as they moved forward in the educational system.

Klesmer (1994) and Vollmer (2000) examine mainstream high school teachers' perceptions of ESL learners and their assessment strategies for determining these students' achievement in content area academic study. What emerges is a stereotypic and somewhat confusing image of ESL learners. These students are seen to be hard-working, persistent, intelligent, "nice," and, at least on the surface, competent in English-judged by conversational abilities and general communicative competence. Consequently, teachers overestimate ESL learners' academic level of proficiency and seem lost when it comes to making sense of students' lower-than-anticipated academic performance. But they are willing to give the ESL students the benefit of the doubt, and also a break. The phenomenon of "goodwill" marks has been identified in the ESL research literature from an early stage. ESL students for their part become adept at coping, much like other unsuccessful readers (Brozo, 1990).

To add to the challenge of reaching at-risk young-arriving ESL students, we have learned from our colleagues, and from our own experience, that many of these students do not perceive themselves as needing ESL support, based on their self-perception of fluency in English conversational skills and their length of residence in Canada. From the perspective of teachers and students alike, it is clear that working in the context of a high school English class is a multifaceted challenge. How were we (and they) to know the collision course they were pursuing as they advanced toward the all-important high-stakes grade 12 provincial English examination, and our date with destiny in the principal's office? 


\section{Context of the Study: Site Description, Profile of ESL Learners, Research Question}

The study took place in a small, academically oriented high school in a large urban setting. There are approximately 1,200 students, evenly divided between junior high (grades 7-9) and senior high (grades 10-12). It is the only school in the city to accommodate both junior and senior high students. The school is centrally located in the city core. The immediate neighborhood children whom the school initially served have long since grown up and moved on. The school now houses a variety of what may be called "specialty" programs-ESL, Deaf and Hard of Hearing (DHH), Gifted and Talented (GATE) - to augment the neighborhood enrollment figures in the school's catchment area. Most students arrive by bus. The school operates on a semester system, well suited to the work at hand.

An ESL program was introduced in September 1997 to serve approximately 85 students, almost exclusively the children of business class immigrants who had recently arrived from the Pacific Rim. Most of these students arrived in their grade 10 year, aged 16, and spoke Cantonese as their first language. They were academically competent and in a hurry to get to university (Roessingh, 1999).

A look in the school cafeteria or any hallway of the study site reveals a significant proportion of visible minority students-perhaps as many as $300-400(25-35 \%$ of the school population). Although some of these students

Table 1

Profile of 3 Cohorts of ESL Learners

\begin{tabular}{|c|c|c|c|}
\hline Cohort & $\begin{array}{l}\text { Immigrant } \\
\text { class }\end{array}$ & $\begin{array}{l}\text { Age on } \\
\text { Arrival }\end{array}$ & Risk profile \\
\hline$A$ & Business & Elementary age & $\begin{array}{l}\text { Little or no ESL support. Academic expectations but } \\
\text { marginal performance throughout high school in } \\
\text { English literature courses. Approximate reading grade } \\
\text { equivalent } 5 \text { on entry to grade } 10 \text {. Failure and dropout } \\
\text { of program at university level. }\end{array}$ \\
\hline$B$ & Business & Elementary age & $\begin{array}{l}\text { Little or no ESL support. Academic expectations. At } \\
\text { risk for academic failure in high school. Approximate } \\
\text { reading GE } 5 \text { on entry to grade } 10 \text {. ESL support } \\
\text { offered to this cohort for grades } 10-12 \text {. }\end{array}$ \\
\hline $\mathrm{C}$ & Business & High school (16) & $\begin{array}{l}\text { New arrivals. Academically competent, "in a hurry" to } \\
\text { go to university. Approximate reading GE } 5 \text { on arrival. } \\
\text { ESL program designed to support academic goals. } \\
\text { Cohort B was integrated with this cohort. }\end{array}$ \\
\hline
\end{tabular}


Table 2

Cohort A Grade 12 English and Mathematics Results, January 1998

\begin{tabular}{lcccccc}
\hline Name & School mark & $\begin{array}{c}\text { English } \\
\text { Exam mark }\end{array}$ & Total & School mark & $\begin{array}{c}\text { Mathematics } \\
\text { Exam mark }\end{array}$ & Total \\
\hline Jane & 71 & 30 & 51 & 44 & 33 & 39 \\
Peter & 69 & 38 & 54 & 65 & 66 & 66 \\
Jimmy & 71 & 46 & 59 & 67 & 64 & 66 \\
Anita & 81 & 50 & 66 & 68 & 61 & 65 \\
Alice & 80 & 48 & 64 & 80 & 74 & 77 \\
Dora & 72 & 45 & 59 & 60 & 61 & 61 \\
Average & 74 & 43 & 59 & 64 & 60 & 62 \\
\hline
\end{tabular}

are Canadian-born Chinese (" $\mathrm{CBC}$ " kids, as the newly arrived students called them, although not in a negative tone), a significant number of these students are young-arriving ESL learners, long since dropped from any official funding list, and for all intents and purposes no longer recognized as ESL students, often not even by themselves. They remain at academic risk nevertheless, and it is these students (Cohort $B$, below) who became the focus of our concern. Table 1 summarizes the profile of the three cohorts of ESL learners under investigation.

In Alberta, as in many other provincial jurisdictions across Canada, all grade 12 students entering university must present a pass mark for an academic English literature course. Hence this course performs a gatekeeping function, sorting those who can from those who cannot. Table 2 displays the results of 6 ESL learners' (Cohort A) grade 12 English literature and grade 12 (academic) mathematics. The final (total) score comprises a provincially set examination that counts for $50 \%$, and the other $50 \%$ of the total is determined by the teacher.

At first glance down the total columns, nothing untoward surfaces. The overall English mark, at 59\%, is within range of what seasoned English teachers expect $(62-65 \%)$ and qualifies the students for university entrance. And the total mathematics score at $62 \%$ is consistent with the typical provincial averages. Closer inspection of these data, however, reveals interesting insights into a pattern of academic achievement we need to understand and respond to appropriately.

The gap between the students' English school-based mark and the examination mark is 31 points: and this had been the cause of the principal's concern. Among our colleagues, veterans in English literature education, a gap of no more than 10 points between the school-based mark and the examination mark is seen as the acceptable range. A second concern relates 
to the average score of only $43 \%$ for these ESL learners on the examination. Finally, the average English mark of 59\%, although fulfilling university entrance requirements, does not realistically reflect the students' abilities to engage in literature-based study at the high school level. Further, it may place the student at academic risk in university because this mark may not realistically reflect the students' linguistic abilities either.

In contrast, the mathematics marks are about average, both on the exam and for the school-based mark, with a gap of only 4 points. The combined total average of $62 \%$ is in line with the provincial average. Our colleagues in the mathematics department at school pride themselves on predicting students' marks on the examination within 3-4 points, and indeed it appears they are capable of doing so, even given the discrepancies of some of the students in our small sample.

Our research question, therefore, related to identifying young-arriving ESL students at risk of academic failure in high school and working collaboratively as a team of ESL and English teachers to devise both programmatic-level responses and responses at the level of instruction and evaluation to address the concerns we saw reflected in these marks. We understood the importance of demonstrating to the students the direct link between their ESL support and their mainstream educational goals, especially in English (Roessingh, 1999). Specifically we sought to:

- prepare students for the demands of a high school literature program;

- use the content of the literature program as a vehicle for developing

language, learning strategies, and underlying concepts;

- use time more strategically in the students' three-year high school

program;

- devise ways of more accurately assessing ESL learners' abilities for the class-based mark.

Below is a description of these elements that we believed would address our ESL learners' needs in the context of their literature program and, most important, to pass the high-stakes examination at the end of the grade 12 literature course.

\section{Intervention}

Identifying the learners with an ESL background who might be at risk in their high school studies did not turn out to be problematic. They were located on the failure lists of grade 10 English literature, as well as by checking the results of Alberta provincial standardized achievement tests (language arts) written by all students at the end of grade 9 . Those who scored in the lower $15 \%$ (an estimated reading grade equivalent of 5 , and on a par with the reading abilities of a high intermediate ESL learner) were invited to receive ESL support. Some students self-selected; fear of failure becomes a strong motivating factor at the high school level for these stu- 
dents. By June 2000, 50 students fitting this learner profile had been identified. In September 1998, however, we began our work with a small cohort of eight younger-arriving students (Cohort B) who joined the ESL program, which at that time comprised almost exclusively older-arriving students (Cohort C). These eight students served as our comparison group to the small cohort of younger-arriving ESL learners who had fared so poorly on the 1998 English examination and who had alerted us to the challenge of improving the achievement outcomes of younger arrivals to begin with (Cohort A). Table 3 summarizes the ESL support that was offered to Cohorts $B$ and $C$ over their three years in high school.

The salient features of this plan include delaying entry into mainstream English literature studies until students had acquired more CALP-like proficiency required for engagement with abstract content materials (and GE 7 on a standardized reading measure), offering a sheltered English 10 class open only to ESL learners paired with an adjunct block of ESL time to continue the development of academic writing skills, and providing for ongoing tutorial support to complement the grade 11 and grade 12 literature courses. At the program level, therefore, the needs of younger-arriving ESL learners (Cohort B) closely mirrored those of the older arrivals (Cohort $\mathrm{C}$ ), and from this perspective, developing a timetable that would suit the needs of all of them was less of an issue. Note that the ESL learners (both Cohort B and C) were provided with between 625 and 750 contact hours throughout their high school years to support the development of their English language proficiency. They remained together for their ESL support throughout high school as well as for sheltered English 10. They were fully integrated for grades 11 and

Table 3

Profile of Progress

\begin{tabular}{lll}
\hline ESL placement & Date & Program Focus \\
\hline Intermediate & Sept. 1998-Jan. 1999 & $\begin{array}{l}\text { Skills booster: } \\
125-250 \text { hours }\end{array}$ \\
& Jan. 1999-June 1999 & $\begin{array}{l}\text { Transitional Academic skills: } \\
125 \text { hours }\end{array}$ \\
Advanced & Sept. 1999-Jan. 2000 & $\begin{array}{l}\text { Sheltered English 10: } \\
\text { 125 hours }\end{array}$ \\
Transitional & & Adjunct ESL support: 125 hours \\
& Jan. 2000-June 2000 & $\begin{array}{l}\text { Tutorial to support grade 11 English: } \\
\text { 125 hours }\end{array}$ \\
Mainstreamed & Sept. 2000-Jan. 2001 & Tutorial to support grade 12 English: \\
& & 125 hours \\
\hline
\end{tabular}


12 English, although they were clustered together where possible. In a small school, this timetabling was made possible by working closely with the guidance department. One counselor was responsible for all the ESL students (Roessingh \& Field, 2000). As a side note, the provincial funding formula for ESL support was amended in the summer of 1999 to include the Cohort B profile ESL learner: an unexpected bonus for our school which by then had identified and was actively working with 50 of these students. Previously, ESL support had been capped at three years.

At the level of instructional planning we met a significant challenge. Older-arriving students in the class already have developed linguistic and cognitive maturity in L1. Their learning task in L2 is, therefore, less onerous; they seek to transfer prior knowledge and learning strategies into acquiring ESL. Younger-arriving students, on the other hand, do not have recourse to L1 to develop concept understanding in L2. In short, they cannot "do the cognitive pushups" in either language. Thus although they have the advantage of "sounding good," they are in essence doubly disadvantaged

To address the learning needs of both younger-arriving and older-arriving ESL learners, we adopted a tripartite framework to guide instructional planning for the development of academic competence for all the students. Figure 1 illustrates the framework. It comprises language, underlying concepts, and learning strategies. This framework permits the integration of the crucial elements of academic competence, using content area materials as a vehicle to contextualize these three elements. And it allows for focused and direct instruction of any one component depending on the needs of the student.

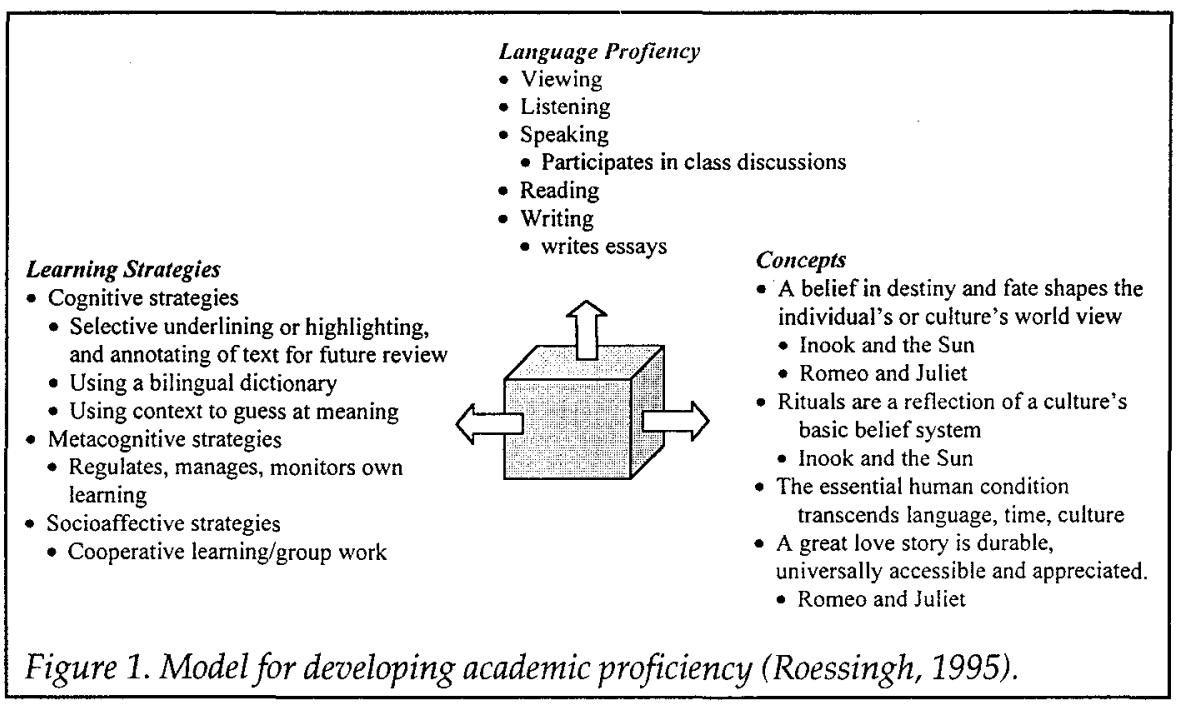


This framework served as a useful planning tool for the ESL and the mainstream English department. Thus although the purview of the English department tended to remain in the area of content instruction, the teachers nevertheless were sensitized to the learning needs of the ESL students in their classes, both during the sheltering phase and while the students were fully mainstreamed in English for the grades 11 and 12 literature courses. The ESL teacher's focus continued to be the provision of support to develop the underlying academic language proficiency (specifically writing), learning strategies, and concepts crucial to the acquisition of content understanding. Collaborative planning and a sense of "teaming" were critical to the success of the overall program and instructional plan. Often content was chosen with the ESL learners in mind, both from the point of view of appropriateness and interest as well as the potential for achieving "more with less." We wanted more depth, less breadth, especially at the grade 10 level. For example, the structure and the elements of the short story were addressed in perhaps five selections rather than the usual 10 or 12 . The assignments were negotiated between the instructors, and often the students' work was passed back and forth to monitor progress, to determine instructional priorities, and to devise assessment strategies that would reflect "where the students were at" in the development of their overall academic competence. On the other hand, as their instructors, we were cognizant of the competition the ESL learners would face once fully mainstreamed and moving toward the provincial examination. Their marks for the ESL adjunct and the English literature courses needed to reflect both of these concerns, and this was sometimes not easy to communicate to the students (and their parents), who expected marks better than the 65-75\% range in English literature.

The following examples illustrate the use of the framework and the collaboration between ESL and English teachers. At the grade 10 level, "Inook and the Sun" (Beissel, 1984) was the modern drama selection. The play embeds a great deal of cultural information about the traditions and rituals that give Inuit life meaning. Thus although ESL learners will have acquired the concept of rituals and traditions, this new and unfamiliar context for these ideas (underlying concepts) requires direct instruction that an English teacher may not have time for, nor be aware of as a learning requirement for the ESL students in the class. The ESL teacher can focus on direct concept instruction through a four-step series of learning tasks (see Appendix).

At the grade 10 level Lee's (1960) To Kill a Mockingbird is replete with idiomatic expressions and unfamiliar vocabulary that make this novel a challenge for ESL learners. What are scuppernogs, charlotte? ESL learners need direct instruction in contextual guessing as a reading strategy to make meaning at the discourse level. They need to know when precision of meaning is important and when it is not. For example, understanding that scuppernogs seem to be a delicacy in southern Black culture of that time is close 
enough; on the other hand, the compliment to the hostess at the tea party related to the sweet and flaky nature of her charlotte must be understood as a comment about the tea pastries, not the hostess's daughter. They need to know which words are worth remembering and which, once momentarily understood (i.e., scuppernogs and charlotte), can be discarded.

And always, developing academic writing skills continued to be a priority. Models, scaffolds, and a process approach to writing both in the ESL setting and the mainstream literature class were adopted as possible ways of improving our students' work. Prewriting activities of posing essential questions (Wiggins \& McTighe, 1998), engaging students in instructional conversations (Saunders, 1999; Goldenberg, 1992-1993), identifying key concepts and vocabulary, brainstorming for supporting evidence, and providing structure and scaffolded support were all part of the instructional planning. Coming up with "big idea" statements (for opening or introductory sentences), narrowing it down, endless practice at writing thesis statements, and connecting concluding comments to introductions were other points for direct instruction.

In sum, our aim was to make our lessons big enough to be inclusive to the needs of all the ESL learners, whether by direct instruction in language, concepts, and strategies or by explicit instruction in the content details (i.e., cultural capital) our learners were missing.

Assessment of our students' progress and achievement had been identified early as a focus of our work. Fewer summative and more formative assessment strategies were adopted. That is, we looked at more work in progress and more work completed both with support and independently in class, taking anecdotal notes on what our students could do on their own, or with help, or with modifications to the assignments. Sometimes, for example, a simple time extension made a difference. A portfolio approach was helpful in asking students to take more responsibility for their learning, to help them note their own progress, and to reflect on their learning. For us as their teachers, portfolios provided concrete evidence of students' progress and an ideal tracking mechanism.

Time, attention to assessment of students' work, collaborative planning, and direct instruction in targeted areas for development in general academic competence were therefore the key elements to our overall strategy for enhancing ESL learners' possibilities for success, most especially as they anticipated their grade 12 English examination.

\section{Preliminary Results: The Expected and the Unexpected}

Our primary goal at the outset of our work had been to improve outcomes on the grade 12 English literature course for younger-arriving ESL learners. Specifically, we had sought to have students achieve marks in the range of $55-60 \%$ on the mandated provincial examination, to reflect our students' 
work more realistically on the school-based mark, and to close the gap between the examination score and the school-based mark: all with the expectation that this would represent the linguistic threshold for success at university. Ongoing tracking of the first small cohort of younger arrivals (Cohort $\mathrm{A}$ ) revealed that although all of them had attempted university-level studies, none had survived beyond the second year of studies, and most had begun to run into academic difficulties even in the first semester.

Table 4 displays the results of the younger-arriving ESL learners with whom we had worked during grades $10-12$, Cohort $B$. Their grade 12 mathematics scores are also displayed.

The average English mark (total) among these learners is $57 \%$ : two points lower than the initial group's average of $59 \%$. The average school mark has dropped from $74 \%$ to $58 \%$, whereas the average exam mark has increased from $43 \%$ to $55 \%$. Although these results appear to reflect more accurately what these ESL learners can achieve in an English literature course (the older-arriving students, Cohort $C$, also achieved marks in this range) and these results were within our set target, we were perplexed about the persistent relative low performance for them compared with their native Englishspeaking classmates. The Examination Manager's Report (Alberta Learning, January 2001) is not yet available; however, previous reports (January and June, 2000 ) record approximately $16 \%$ of all students who sit the examination achieve the standard of excellence of $80 \%$ or better on the examination, a standard none of the ESL learners achieved regardless of their age at arrival. And the range and average of ESL learners' examination scores are clustered below the average (approximately $65 \%$ ) for the general high school population who write the exam.

Table 4

Cohort B: English and Mathematics results, January 2001

\begin{tabular}{lcccccc}
\hline Name & School mark & $\begin{array}{c}\text { English } \\
\text { Exam mark }\end{array}$ & Total & School mark & $\begin{array}{c}\text { Mathematics } \\
\text { Exam mark }\end{array}$ & Total \\
\hline Harry & 60 & 45 & 53 & 95 & 83 & 93 \\
Teresa & 58 & 45 & 52 & 71 & 63 & 67 \\
Sammy & 53 & 48 & 51 & 50 & 26 & 45 \\
Manny & 64 & 53 & 59 & 87 & 78 & 85 \\
Jade & 50 & 54 & 52 & 67 & 55 & 65 \\
Louis & 57 & 63 & 60 & 77 & 61 & 74 \\
Brenda & 60 & 64 & 62 & 78 & 64 & 75 \\
Mike & 61 & 64 & 63 & 62 & 40 & 58 \\
Average & 58 & 55 & 57 & 74 & 59 & 70 \\
\hline
\end{tabular}


We examined the subscores on the English examination. The examination consists of two parts (A and B): a written response, which provides an opportunity for students as readers to respond to a selection in the context of a given topic; and a reading component (70 multiple-choice questions), which tests students by way of curriculum content and thinking (process). Although students in Cohort B who wrote the examination in January 2001 fared much better on the written response than the Cohort A students' performance in 1998, their scores on the multiple-choice questions continued to be dismal, consistently failing or achieving only marginal pass marks on this component of the examination. In fact, the average score on the multiplechoice questions increased slightly from $32 / 70(45 \%)$ in 1998 to $35 / 70(50 \%)$ in 2001. Students are asked to understand content classified as meanings, critical response, and human experience and values at the literal level, the inference level, and the evaluation level. Although unable at this stage of our work to analyze the students' individual responses to each multiple-choice question, we noted in general their poor showing on part B across all three content categories, and in particular the critical response questions. The following examples from the multiple-choice section of previous examinations illustrates the challenge to ESL learners.

The students are given the opening 110 lines of Oscar Wilde's (1988) The Importance of Being Earnest. Questions 1 to 12 in the questions booklet are based on this excerpt. Question 9 asks: The context suggests that when Cecily remarks "In fact, I am going to be his" (line 75), she means that she will (a) look after Ernest, (b) challenge Ernest, (c) belong to Ernest, (d) bewitch Ernest.

Students reading at a literal level, as ESL learners often do, are drawn to choose (c). These students fail to make the inferential leap required to understand that Cecily means that she will become Ernest's guardian-hence look after him-and correctly choose (a). The students would have had to return to line 73 to make this connection, a strategy that apparently escapes the ESL learner working independently in an examination setting.

Areas that present extreme difficulties for ESL learners relate to identifying tone and mood, close reading as is required for evaluation-type questions (as there may be an element of truth in one or more of the alternatives in this type of question), and reading for specific detail. And always, a restricted vocabulary hinders ESL learners (e.g., attributing motive for doing something to the desire to pacify, irritate, question, or ridicule someone). Interpreting unfamiliar cultural perspectives, as in excerpts from Pride and Prejudice (Austen, 2001) or the novel The Moviegoer (Percy, 1961) is another example where ESL learners encounter difficulties.

The ESL students' mathematics scores tell a different story. These scores show an increase over the initial group's mathematics school-based average of $64 \%$. It should be noted that the provincial ministry of education had 
introduced a new mathematics curriculum, and the accompanying provincial examination (weighted for $20 \%$ rather than the usual $50 \%$ ) was being piloted in January 2001. Although the results were disappointing, our colleagues in the mathematics department seem confident in their abilities to assess students' mathematics proficiencies regardless of the curriculum and assure us that the school-based portion of the final mathematics mark reflects the students' ability to "do the math." By this measure, the ESL learners' mathematics scores have increased by $10 \%$ : a significant increase in a mathematics instructor's assessment. This was an unexpected outcome.

A second unexpected outcome related to the younger-arriving ESL learners' (Cohort B) improvement in their L1. Although we did not measure L1 proficiency either at intake in grade 10 or three years later, anecdotal evidence (provided by reports from the older arrivals' assessments of their classmates' "baby-like" L1) and the students' self-assessment suggests improvement in their use of their L1. We noticed that as these students came to see themselves as needing ESL support, they were more open to befriending and interacting with older-arriving ESL learners, who comprised most of the students in the ESL program. Often their preferred language for social interaction and even for explaining difficult concepts to each other was Cantonese (sometimes Mandarin-we had speakers of both). The older arrivals were initially surprised by both the restricted level of the younger arrivals' L1 and their need for ESL support even after so many years of residence in Canada. The issue needed some sensitive discussion.

A related issue for the younger arrivals of Cohort B involved their identity as learners in the mainstream settings. Truly, who are they? Underachievers? Failures? Misidentified? Misunderstood? Or worse, losers? Are they Canadian? Ethnics? Ethnic Canadian? Their parents often placed unreasonable pressure on these students to work harder and perform better. Even to themselves these students often seemed strangers in search of who they might be and who they might yet become. We noticed an unfolding sense of confidence, perhaps given to them by a sense of belonging and self-understanding for the first time in years. These students readily joined in social activities organized for the ESL learners, befriended one another, and participated enthusiastically in their graduation festivities as a group bent on celebrating their achievement, their success, and their future plans for university attendance. We noticed an increased willingness to dedicate their efforts to homework and in-class work, perhaps both as a result of the modeling of the older-arriving students who were so driven to do well and also their new-found self perception as successful (although not strong) academic learners in a literature class. 


\section{Interpretation and Discussion}

Our work leads us to challenge some commonly held beliefs about secondlanguage acquisition. The "younger the better" belief may need to be supplemented with the proviso, "It's never too late." The notion of a critical window and the crucial importance of uninterrupted cognitive development in L1 might also be questioned. It would appear that even after years of unsupported mainstream placement and little or no further development in L1, some ESL learners' potential can be reclaimed and they can at least partly make up for lost time.

It would seem that the development of English language proficiency is central to learning across the curriculum. This finding is not entirely new: as long ago as the Bullock Report (Great Britain, Department of Science and Education, 1975), the role of language in learning across the curriculum was identified as crucial to academic success. Further research needs to be done to affirm our initial impression that the increase in mathematics scores may be a consequence of the students' enhanced level of language: language that is critical to reading for problem-solving, for example. It may be that the initial reading scores of approximately GE 5 were below the threshold required to succeed in the mathematics curriculum as the demand for reading increased.

We are intrigued by the idea that providing more mature and proficient L1 role models in the immediate peer group in the ESL setting and promoting the use of $\mathrm{Ll}$ in certain informal social contexts as well as for specific learning tasks associated with concept acquisition seems to have had a positive impact on L2 development and success with the English literature curriculum. It may be that as these younger arrivals developed more CALPlike proficiency in L1, they, like their older-arriving ESL classmates, were able to transfer concept information and learn more efficiently in L2.

We are discouraged by the continued poor showing on part $B$ of the English literature examination. The findings suggest that teaching cultural information critical to understanding human experience and values is a much more complex undertaking than we had previously thought. Even explicit unmasking of many culturally embedded references, images, and metaphors does not guarantee that, in a novel context, our ESL learners will recognize the salient underlying understandings and apply and transfer them appropriately. To know a culture, must one be of that culture? And, we wondered, what culture is relevant (L1 or L2) in helping our young ESL learners understand and make sense of their world by way of the narratives we use to teach? In this sense, younger-arriving ESL learners may face significant challenges in school every day. On a related theme, we wonder about their sense of self and their shaping identities in a school and academic culture that does not favor or privilege them. Our questions relate to 
Cummins' (1981) identification of the negative consequences of ESL learners' inability to identify comfortably with either home or Canadian language and culture.

\section{Conclusion}

It may not be too late to help younger-arriving ESL learners reclaim their academic potential, even after many years of what appears to be a low plateau (typically around a grade 5 level) and fossilization. They can make progress, albeit slow, until they reach what we came to call "the wall." They must do so without recourse to their first language, which in most cases here has not developed beyond the level required for simple daily conversation. This wall appears to relate to cultural capital (rather than lack of linguistic resources) that our students have not acquired and continue to struggle to attain. The question about the fairness of the cultural content of the examination and the inability of our educational institutions to reflect and value diversity needs further examination.

Failure to offer ESL learners realistic and fair feedback on their performance leads to devastating consequences that may have lifelong effects. This means that for younger-arriving ESL learners, careful monitoring of their growth and achievement is necessary, especially in the upper elementary and junior high grades. Using the results of standardized measures is a simple way of quickly identifying ESL learners who may be at academic risk.

Integrating younger-arriving ESL learners with older-arriving ESL students may be a successful strategy for enhancing L1 development, which in turn may facilitate language and concept development in L2. Perhaps more powerful is the gift of identity that many of our younger-arriving students have lost sight of in the intervening years. As we grew to understand from interpreted conversations with their parents, nothing was more important to them than the families' reclaiming of "face" (pride in their children's academic success and university attendance).

Additional challenges are identifying the students and garnering the support from administration to commit the time for the ESL support to the school timetable and the allocation of staff are additional challenges. Although some might ask, "Can we afford it?" our resounding thought is "How can we not?" To do less would be to squander the precious human resources of our nation's future and to deny access to the opportunity structure afforded by society to generations of children who will never know who and what they might have become in their adopted second home.

\section{Acknowledgments}

The authors would like to thank the principal of the school, Diane Field, for her concern, care, and support of the ESL and English Department's work in improving teaching and learning for ESL learners. Her monitoring of the English examinations alerted us to the need for this work. 
We are grateful for the feedback from the anonymous readers who reviewed our manuscript. Their suggestions were helpful in strengthening the presentation of our work. And last, we owe a debt of gratitude to Sandie Kouritzin and Pat Mathews, co-editors of the TESL Canada Journal, for their encouragement and gentle prodding to bring our work to completion and publication.

\section{The Authors}

Hetty Roessingh is a long-time ESL practitioner with the Calgary Board of Education. Her interests in classroom-based research have evolved from tracking to curriculum design and development, materials design and development to assessment, and always advocacy. In July 2000 , Hetty joined the Faculty of Education, University of Calgary, where she teaches in the MEd TESL program.

Pat Kover is the English Department head at Queen Elizabeth High School, Calgary. Pat's interest in classroom-based research as a way of understanding teaching and learning for ESL students in mainstream settings made for a natural collaboration with the ESL program. In the teaching-learning cycle, the next question has already emerged, and Pat is busily unearthing the data required to understand the notion of "cultural capital."

\section{References}

Alberta Learning. (2000). English 30 and Mathematics 30, Examination manager's report. January 2000 and June 2000 Diploma examination results. Retrieved July 19, 2001, from www.learning.gov.ab.ca/k_12testing/diploma/emr_2000/default.asp

Austen, J. (2001). Pride and prejudice. New York: Norton (Original work published 1813).

Beissel, H. (1984). Inook and the Sun. In B. Cameron (Ed.), On Stage 1 (pp. 271-300). Scarborough, ON: Globe Modern.

Brozo, W. (1990). Hiding out in secondary content classrooms: Coping strategies of unsuccessful readers. Journal of Reading, 33, 324-328.

Collier, V. (1995). Acquiring a second language for school. Directions in Language and Education, National Clearinghouse for Bilingual Education, 1(4). Retrieved May 5, 2001, from www.ncbe.gwu.edu/ncbepubs/directions/04.htm

Cummins, J. (1981). Bilingualism and language minority children. Toronto, $\mathrm{ON}$ : Ontario Institute for Studies in Education.

Cummins, J. (1982). Tests, achievement and bilingual students. Focus No. 9, February 1982. Wheaton, MD: National Clearinghouse for Bilingual Education.

Employment and Immigration Canada. (1985). Annual report to Parliament on future immigration levels. Ottawa: Author.

Goldenberg, C. (1992-1993). Instructional conversations: Promoting comprehension through discussion. Reading Teacher, 46, 316-326.

Frayer, D., Frederick, W.G., \& Klausmeier, H. (1969). A schema for testing the level of cognitive mastery. Working paper No. 16. Madison, WI: Wisconsin Research and Development Center.

Great Britain, Department of Science and Education. (1975). A language for life: Report of the committee of inquiry appointed by the Secretary of State for Education and Science, chaired by A. Bullock. London: Author.

Klesmer, H. (1994). Assessment and teacher perceptions of ESL student achievement. English Quarterly, 26(3), 8-11.

Krashen, S., Long, M. \& Scarcella, R. (1979). Age, rate and eventual attainment in second language acquisition. TESOL Quarterly, 13, 573-582.

Lee, H. (1960). To kill a mockingbird. New York: Warner.

Olague, D. (1993). Gifted and denied. Gifted Child Today, May/June, 47-48.

Neu, D., \& Taylor, A. (2000). Funding mechanisms, cost drivers and the distribution of education funds in Alberta: A case study. Alberta Jurnal of Educational Research, 46, 214-232. 
Oyama, S. (1976). A sensitive period for the acquisition of a non-native phonological system. Journal of Psycholinguistic Research, 5, 261- 85.

Percy, W. (1961). The moviegoer. New York: Knopf.

Roberts, C. (1994). Transferring literacy skills from L1 to L2: From theory to practice. Journal of Educational Issues of Language Minority Students, 13, 209-221. Retrieved May 5, 2001, from http://www.ncbe.gwu.edu/miscpubs/jeilms/vol13/transf13.htm

Roessingh, H.(1995). Teaching to diversity: Meaningful inclusion of ESL students in high school mainstream settings. Exceptionality Education, 5(1), 65-83.

Roessingh, H. (1999). Adjunct support for high school ESL learners in mainstream English classes: Ensuring success. TESL Canada Journal, 17(1), 72-86.

Roessingh, H., \& Field, D. (2000). Time, timing, timetabling: Critical elements of successful graduation of high school ESL learners. TESL Canada Journal, 18(1), 17-31.

Saunders, W. (1999). Successful transition into mainstream English: Effective strategies for studying literature. Retrieved May 5, 2001, from http://www.cal.org/crede/pubs/edpractice/EPR2.pdf

Snow, C., \& Hoefnagel-Hohle, M. (1978). The critical period of language acquisition: Evidence from second language learning. Child Development, 49, 114-28.

Vollmer, G. (2000). Praise and stigma: Teachers' constructions of the "typical ESL student." Journal of Intercultural Studies, 21(1), 54-66.

Wiggins, G., \& McTighe, J. 1998. Understanding by design. Retrieved August 15, 2001, from www.ascd.org/readingroom/books/wiggins98book.html

Wilde, O. (1988). The importance of being earnest. New York: Chelsea House (Original work published 1899). 


\section{Appendix}

\section{A Four-Step Sequence for Concept Teaching}

These four learning tasks can be used to crystallize, manipulate, and expand key concepts. They can be used in a variety of ways (individual or partner work, for teaching or testing understanding). They help demonstrate relationships within a key concept and work toward precision of meaning.

1. Frayer Model (1969)*

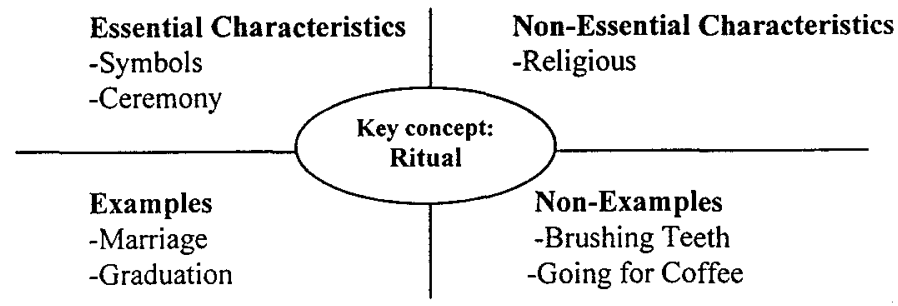

2. Odd Man Out

Marriage Baptism Brushing your teeth Graduation

3. Analogies

Ring = Marriage

Diploma $=$

4. Semantic Webbing

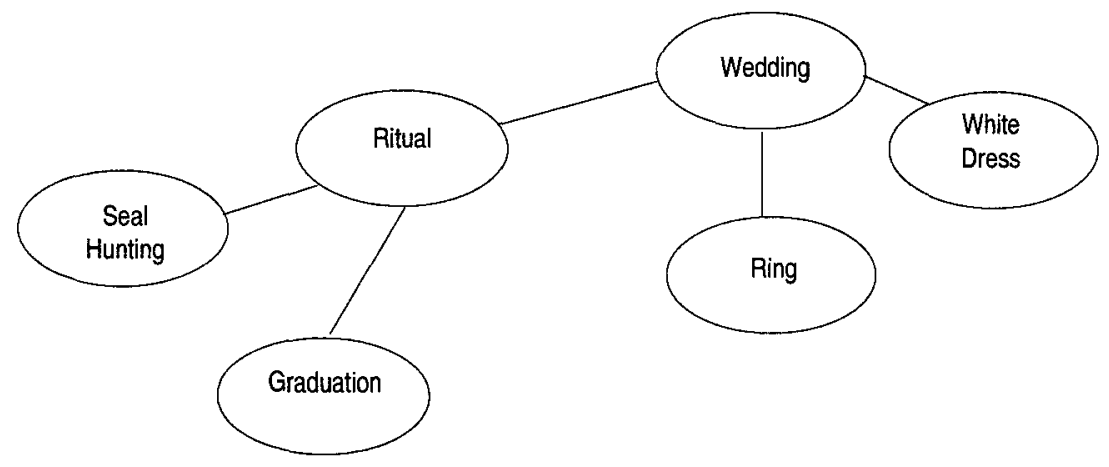

*Frayer, Frederick, \& Klausmeier (1969). 